\title{
As mulheres nos esportes olímpicos: olhares da imprensa carioca (1920-1935)
}

\author{
Women in Olympic Sports: \\ Looks of the Carioca Press (1920-1935)
}

Fausto Amaro Ribeiro Picoreli Montanha

Universidade Estadual do Rio de Janeiro, Rio de Janeiro/Brasil

Doutor em Comunicação, UERJ

faustoarp@hotmail.com

\begin{abstract}
RESUMO: Neste artigo, investigo as narrativas da imprensa carioca sobre a participação feminina no campo esportivo, mais especificamente nos esportes olímpicos entre os anos de 1920 e 1935. Trata-se de um recorte de pesquisa mais ampla, que investigou o campo olímpico carioca entre os anos de 1890 e 1935. Com base na análise de jornais e revistas cariocas desse período (1920-1935), busco situar a representação do feminino e a postura dos jornalistas e outros atores diante de uma presença cada vez maior de mulheres na esfera do esporte. Como conclusão, pude verificar que a abordagem temática no esporte (graça, beleza, maternidade) não diferia do que era esperado socialmente da mulher à época. Jornalistas e dirigentes esportivos se opunham explicitamente aos avanços femininos no esporte e acionavam argumentos pseudocientíficos baseados na tradição para justificar seus posicionamentos.
\end{abstract}

PALAVRAS-CHAVE: Esporte; Mulher; Narrativas; Imprensa; Jogos Olímpicos.

ABSTRACT: In this article, I investigate the narratives of the press from Rio de Janeiro about the female participation in the sports field, more specifically in Olympic sports between 1920 and 1935. It is a piece of a broader research that investigated the Rio Olympic field between the years of 1890 and 1935. Based on the analysis of Rio de Janeiro newspapers and magazines of this period (19201935), I seek to situate the representation of the feminine and the posture of journalists and other actors faced with an increasing presence of women in the sphere of sport. As a conclusion, I could verify that the thematic approach in sport (grace, beauty, maternity) did not differ from what was expected socially from women at the time. Journalists and sports officials were explicitly opposed to women's advances in sports and triggered pseudo-scientific and tradition-based arguments to justify their positions.

KEYwoRDS: Sport; Woman; Narratives; Press; Olympic Games. 


\section{INTRODUÇÃO ${ }^{1}$}

Este artigo representa um dos desdobramentos da pesquisa que desenvolvi ao longo do período de doutoramento em Comunicação. Nessa oportunidade, investigava as relações entre a imprensa carioca e a formação de um campo olímpico na cidade do Rio de Janeiro. Das muitas surpresas de pesquisa, uma das que mais despertou meu interesse foi a forma como os jornalistas abordavam a gradativa entrada da mulher no mundo esportivo, principalmente a partir da década de 1920. Uns com certo desdém, outros com receio e outros tantos com ferrenha oposição. Não foi deveras um caminhar tranquilo para as atletas, pelo menos até o ano de 1935, no qual se encerrou minha pesquisa.

Em princípio, essa "descoberta" figuraria acanhada em minha tese, porém julguei relevante discorrer um pouco mais sobre ela, o que rendeu um subitem no último capítulo daquele trabalho. As reflexões que apresento aqui são fruto desse texto original, acrescidas da leitura posterior de novas referências bibliográficas. ${ }^{2}$

Como já deixei entrevisto, este artigo busca tão somente apresentar criticamente as narrativas de jornais e revistas da cidade do Rio de Janeiro acerca da participação olímpica de atletas do sexo feminino, cotejando-as, sempre que possível, com o material oficial produzido pelo Comitê Olímpico Internacional (COI). ${ }^{3}$ Ainda que minha pesquisa doutoral tenha se estendido na análise do período entre 1890 e 1935, neste artigo investigo apenas o intervalo entre 1920 e 1935, pois mais profícuo em discursos relacionados à presença da mulher no esporte olímpico.

\footnotetext{
${ }^{1}$ Versão revisada do trabalho apresentado no GP Comunicação e Esporte, XVIII Encontro dos Grupos de Pesquisas em Comunicação, evento componente do $41^{\circ}$ Congresso Brasileiro de Ciências da Comunicação.

${ }^{2}$ Um destaque especial deve ser dado ao artigo "Desafios e percalços da inserção da mulher nos Jogos Olímpicos (1894-1965)", escrito por Sérgio Giglio e outros colaboradores. Trata-se de um trabalho de grande fôlego, que investigou historicamente a participação feminina no mundo olímpico, tanto no cenário internacional quanto no Brasil. É uma pesquisa mais ampla em seu escopo, porém focada apenas na documentação oficial (relatórios e boletins do COI, leis brasileiras, escritos de Coubertin). Acredito que o presente artigo venha a complementar e enriquecer algumas das contribuições de Giglio.

${ }^{3}$ Os veículos consultados na Hemeroteca Digital da BN foram os seguintes: Jornal do Brasil, O Paiz, Gazeta de Notícias, Revista da Semana, Correio da Manhã, O Imparcial, O Malho, Careta, Sport Illustrado, Fon Fon, Eu sei tudo, O Jornal, Jornal dos Sports, A Noite.
} 


\section{“O SPORT É NECESSÁRIO AO SEXO FRACO?”: AS MULHERES NOS JOGOS OLÍMPICOS}

A participação de mulheres no esporte apresentou significativo incremento nas décadas de 1920 e 1930, o que pode ser comprovado na imprensa carioca pelo aumento exponencial nas referências a atletas mulheres, eventos voltados ao esporte feminino e artigos sobre a presença da mulher nos estádios. 0 "silêncio" anterior da imprensa quanto às mulheres no campo olímpico carioca diz muito sobre o lugar social reservado ao sexo feminino. Isso não quer dizer, no entanto, que não havia ação feminina nos esportes antes de 1920. Victor Melosinaliza para a presença de mulheres ciclistas em provas mistas no Frontão Velocipédico Fluminense ainda na década de $1890 .^{4}$ No início do século XX, mulheres musculosas, que rompiam com o padrão de corpo feminino, e campeonatos bemsucedidos de luta entre mulheres já compunham o horizonte das práticas esportivas femininas. ${ }^{5}$

Segundo Silvana Goellner, a "inserção das mulheres brasileiras no mundo do esporte data de meados do século XIX. No entanto, é a partir das primeiras décadas do século XX que a participação se amplia adquirindo, portanto, maior visibilidade". ${ }^{6}$ Fabiano Devide, em artigo sobre o desenvolvimento da natação feminina no começo do século XX, identifica já naquele período a presença de textos na imprensa carioca e paulista versando sobre a importância da prática física para as mulheres. No entanto, conforme ressalta o próprio autor, essa não era a regra, mas a exceção. ${ }^{7}$

A constatação de que o esporte moderno é um território dominado por homens (brancos e ocidentais, mais especificamente) recebe suporte de vários autores. Segundo Richard Giulianotti, o "esporte moderno sempre foi um domínio cultural crucial para a construção e reprodução de identidades masculinas heterossexuais dominantes". ${ }^{8}$ Nancy Theberge, por sua vez, aponta que:

\footnotetext{
${ }^{4}$ MELO. Corpos, bicicletas e automóveis, p. 78-79.

${ }^{5}$ MELO. Corpos, bicicletas e automóveis, p. 84-85.

${ }^{6}$ GOELLNER. Mulher e esporte no Brasil, p. 86.

${ }^{7}$ DEVIDE. A natação como elemento da cultura física feminina no início do século XX, p. 128.

${ }^{8}$ GIULIANOTTI. Sport, p. 80. "Modern sport has always been a crucial cultural domain for constructing and reproducing dominant, heterosexual masculine identities". As traduções deste artigo são de minha autoria.
} 
"Historicamente, o esporte tem sido organizado como uma reserva masculina, na qual a maioria das oportunidades e recompensas vai para homens". ${ }^{9}$ Desde sua gênese, nas escolas públicas britânicas (boys' public schools) no final do XIX, o esporte era um espaço para a socialização e difusão de valores vistos como masculinos (competitividade, força, virilidade). Em contraponto, as mulheres inglesas na Era Vitoriana estavam atreladas ao signo da fragilidade, um mito duradouro na história do esporte feminino. ${ }^{10}$

Os avanços femininos no esporte acompanharam as conquistas mais amplas da 1a onda feminista (década de 1850 a 1930), que garantiu direitos importantes para as mulheres, como o "sufrágio político, educacional e as oportunidades de emprego".11 Além disso, as primeiras edições olímpicas coincidiram "com os anos formativos do esporte organizado para mulheres no Ocidente".12 No campo acadêmico, os estudos sobre a mulher no esporte foram impulsionados pelas teorias feministas, ${ }^{13}$ notadamente a partir da década de 1970. Jennifer Hargreaves identifica um "núcleo comum" de aplicação da teoria feminista no esporte, a saber: "expor, desafiar e eliminar as políticas e práticas dominantes baseadas no gênero". ${ }^{14}$ Ainda que nem toda pesquisa sobre mulheres esportivas seja feminista, conforme salienta Susan Birrell, ${ }^{15}$ é interessante notar que a perspectiva feminista atua na práxis esportiva, isto é, almeja a mudança social no esporte.

A ascensão das mulheres no meio esportivo foi gradual e obstaculizada por preconceitos e forças políticas contrárias. Nas descrições jornalísticas coligidas para este artigo, expressões como "belo sexo", "sexo fraco", "sexo frágil" e "sexo débil" reiteravam estereótipos sobre a mulher. Mesmo matérias de exaltação ao triunfo esportivo feminino mesclavam imagens de fraqueza e fortaleza, como fica claro neste trecho: "Muitas têm sido, pois, no mundo sportivo, as coroas de louros

\footnotetext{
${ }^{9}$ THEBERGE. Gender and Sport, p. 323. "Historically, sport has been organized as a male preserve, in which the majority of opportunities and rewards go to men".

10 THEBERGE. Gender and Sport, p. 322.

${ }^{11}$ GIULIANOTTI. Sport, p. 84. "political suffrage, educational and employment opportunities".

12 HARGREAVES. Sporting Females, p. 210. "with the formative years of organized sports for women in the West".

${ }^{13}$ Birrell (2007, p. 61) defende que se fale em teorias feministas, no plural, uma vez que existem abordagens liberais, radicais, marxistas, socialistas sobre o feminismo.

${ }^{14}$ HARGREAVES. Querying Sport Feminism, p. 187. "to expose, challenge and eliminate gender-based dominant policies and practices".

${ }^{15}$ BIRRELL. Feminist Theories for Sport, p. 63.
} 
colocadas nestes últimos tempos sobre femininas, frágeis e fortes cabeças!". ${ }^{16}$ Esse excerto corrobora ainda o paradoxo ameaça/complementaridade verificado por Goellner, segundo o qual:

a presença da mulher no mundo do esporte representa [...] ameaça porque chama para si a atenção de homens e mulheres, dentro de um universo construído e dominado por valores masculinos e porque põe em perigo algumas características tidas como constitutivas da sua feminilidade. Complementaridade porque parceira do homem em atitudes e hábitos sociais, cujo exercício simboliza um modo moderno e civilizado de ser. ${ }^{17}$

Um expediente comum era separar os esportes entre aqueles aptos à prática feminina e os não recomendados. Vejamos, por exemplo, a opinião da jornalista de pseudônimo Majoy ${ }^{18}$ na coluna "Modas e Interiores" sobre esse assunto: "Cito justamente o tênis por ser entre todos os jogos elegantes o mais gracioso, o que mais se presta as atitudes moças naturais, inesperadas e, portanto, as mais belas". ${ }^{19}$ A separação entre esportes aptos e proibidos para as mulheres, por mais anacrônico que possa parecer, persistiu até a década de 1980, quando a prova feminina de três mil metros não foi incluída no programa olímpico do atletismo, sob a alegação de que era “'um pouco extenuante para as mulheres' e afetaria negativamente seu metabolismo". ${ }^{20}$

O esporte, quando disputado por mulheres, deveria atender a uma série de restrições, visando preservar um padrão estabelecido de corpo e cumprir um propósito socialmente imposto, qual seja, o da mulher-mãe, limitada ao ambiente doméstico. É por esse motivo que, como ressalta Goellner, eram aceitáveis para as mulheres "apenas as práticas corporais e esportivas que buscavam, senão potencializar, pelo menos evidenciar uma feminilidade que, vinculada à beleza e à graciosidade, também lhes conferissem 'gestualidades e comportamentos considerados adequados à sua natureza"'.21

\footnotetext{
${ }^{16}$ Correio, 24 mar. 1929, p. 5.

${ }^{17}$ GOELLNER. Mulher e esporte no Brasil, p. 89.

${ }^{18}$ A jornalista Sylvia Bittencourt, esposa do dono do Correio da Manhã Paulo Bittencourt era quem assinava essa coluna. Fonte: https://bit.ly/2QkEAyQ. Acesso em: 20 dez. 2019.

${ }^{19}$ Correio, 06 ago. 1924, p. 2.

${ }^{20}$ HARGREAVES. Sporting Females, p. 217. '“a little too strenuous for women' and adversely affect their metabolismo".

${ }^{21}$ GOELLNER. Jogos Olímpicos, p. 33.
} 
Fotografias de atletas mulheres em treinamento ou competição se multiplicavam pelas publicações cariocas nas décadas de 1920 e $1930 .^{22}$ No entanto, mesmo nesses espaços, o lugar de fala masculino era predominante. Na legenda de algumas imagens, como as que reproduzo abaixo, figurava antes de qualquer outra informação o julgamento valorativo do jornal: “O BOM FEMINISMO” (assim mesmo, em caixa alta). Cabe situar duas possíveis abordagens para essa expressão: simples apreço pelo movimento feminista ou indicação do esporte como local ideal para as manifestações do feminino. Corroborando essa segunda asserção, o jornalista Mario Mello compartilhava sua opinião sobre o tema: "Somos, porém, dos que julgam o feminismo um grande bem quando entendida a sua significação no bom sentido, num sentido racional, lógico, produtivo, forte, cativante e agradável. Esse sentido é o feminismo no sport". ${ }^{23}$ A perspectiva de análise nesses casos é reveladora de que também o jornalismo era um campo marcadamente masculino. ${ }^{24}$
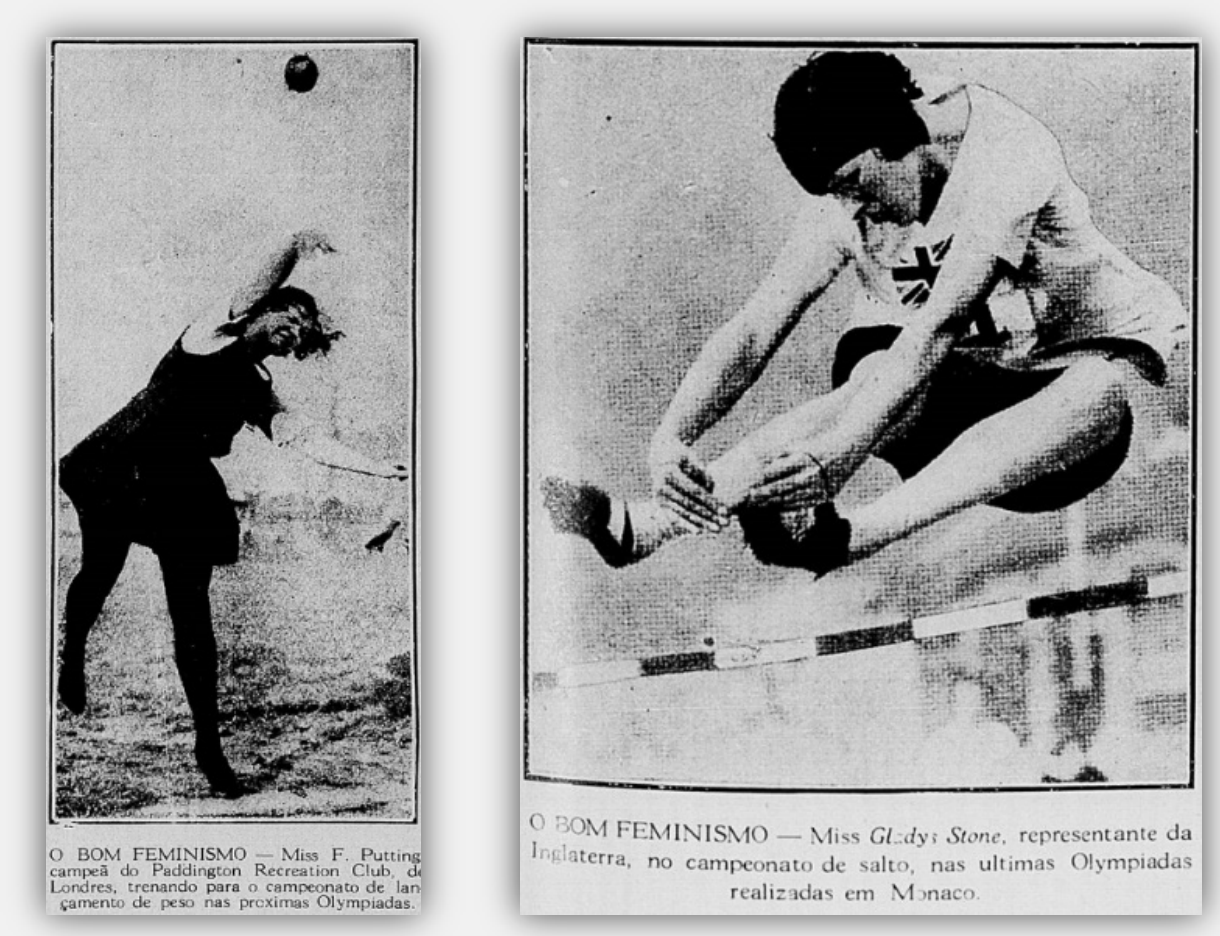

Figura 1 - Fotos de atletas mulheres sinalizam para uma mudança no campo esportivo. Fonte: Eu sei tudo, junho 1922, p. 53 (à esq.); Eu sei tudo, dezembro 1923, p. 25 (à dir.).

\footnotetext{
${ }^{22}$ Cumpre destacar, conforme Devide (2004, p. 132), que "a maior parte das atletas brasileiras era fotografada parada, com o traje de jogo e equipamentos, mas não em ação", o que, segundo o autor, se justifica como parte de "uma rede de estratégias para manter a graciosidade feminina, ao lado da prática esportiva não-competitiva".

23 O Paiz, 28 jul. 1926, p. 7.

${ }^{24}$ HORNE et al. Understanding sport, p. 162.
} 
A entrada das mulheres nos Jogos Olímpicos era interpretada analogamente, isto é, com curiosidade e temor. Lembremos que, desde sua fundação, o COI é uma "instituição antidemocrática, autorregulada e dominada por homens". ${ }^{25}$ Oficialmente, a entidade admitiu a presença de atletas do sexo feminino apenas a partir da segunda edição dos Jogos, em Paris, e, mesmo assim, em poucos esportes. Até 1920, ainda eram bastante limitados os esportes olímpicos permitidos às mulheres: golfe e tênis desde Paris (1900), tiro com arco a partir de St. Louis (1904), patinação artística desde Londres (1908) e natação a partir de Estocolmo (1912). A esgrima apareceria apenas em Paris (1924) e o atletismo, timidamente, em Amsterdã (1928). ${ }^{26}$ Segundo Hargreaves, as "dificuldades particulares dos esportes olímpicos para as mulheres tendem a ser exemplos exagerados de problemas e complexidades intrínsecas ao esporte feminino em geral". ${ }^{27}$

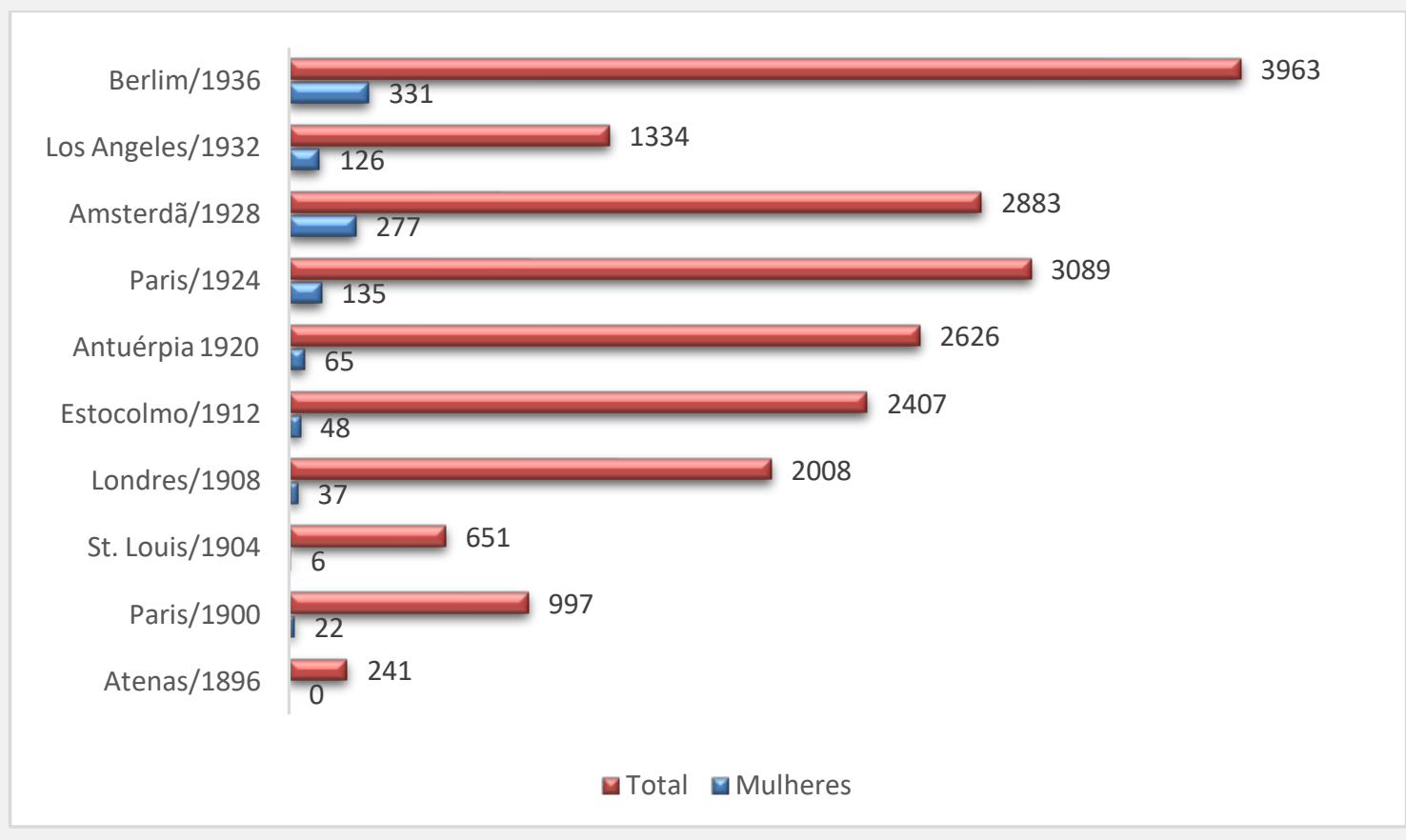

Tabela 1 - Evolução da participação feminina nos Jogos. ${ }^{28}$

Fonte: Dados disponíveis no site do COI; tabela elaborada pelo autor.

\footnotetext{
${ }^{25}$ HARGREAVES. Sporting Females, p. 209. "Since its foundation in 1894, it has been an undemocratic, self-regulating and male-dominated institution".

${ }_{27}^{26}$ PIEROTH. Los Angeles 1932, p. 96.

${ }^{27}$ HARGREAVES. Sporting Females, p. 209. "The particular difficulties of Olympic sports for women have tended to be exaggerated examples of problems and complexities intrinsic to women's sports in general".

${ }^{28}$ A informação sobre o número de atletas mulheres em St. Louis/1904 não se encontra no site do COI. No entanto, o dado informado (seis) pode ser conferido em inúmeras fontes, dentre elas Toohey e Veal (2007, p. 199).
} 
O próprio fundador das Olímpiadas Modernas, Pierre de Coubertin, impunha oposição sistemática à participação olímpica feminina, o que se refletia no baixo número de mulheres nas primeiras edições dos Jogos. Até 1935, apenas 716 atletas do sexo feminino haviam competido em Olimpíadas, ante um total de 15.520 homens (vide tabela 1). Em textos enviados à imprensa e nas publicações oficiais do COI, Coubertin expunha suas impressões sobre a presença feminina no campo olímpico. Após as participações olímpicas de mulheres entre 1900 e 1908, vejamos o que o presidente do COI afirmava em artigo para a Revue Olympique, edição de julho de 1912:

Pensamos que os Jogos Olímpicos devem ficar reservados aos homens [...] Não há somente jogadoras de tênis e nadadoras, há também amazonas e praticantes de esgrima, e na América, remadoras. É possível que haja em um futuro próximo corredoras e até mesmo mulheres que joguem futebol? A prática destes esportes por mulheres seria um espetáculo recomendável ante a multidão que uma Olimpíada reúne? Não pensamos assim. ${ }^{29}$

Nesse mesmo artigo, elencando as dificuldades financeiras e logísticas de organizar uma Olimpíada feminina, Coubertin arrematava: "Nada prático, nada interessante, nada estético, e não tememos acrescentar: incorreto; como seria a partir do nosso ponto de vista essa Olimpíada feminina". ${ }^{30}$ Se para Coubertin bastava "o aplauso feminino como recompensa", não era isso o que as mulheres de sua época pensavam. ${ }^{31}$ A impraticabilidade de Jogos Olímpicos femininos se revelaria um prognóstico equivocado, uma vez que coletivos femininos se juntaram e organizaram competições esportivas exclusivamente para mulheres ainda na década de 1920.

No período investigado neste artigo, diversos grupos feministas exerciam pressão cada vez maior pela abertura do esporte à participação das mulheres. A principal ativista dessa causa era a francesa Alice Milliat. Seu objetivo mais imediato era a inclusão do atletismo feminino no programa olímpico de 1920.

\footnotetext{
${ }^{29}$ COUBERTIN. Pierre de Coubertin, p. 703.

${ }^{30}$ COUBERTIN. Pierre de Coubertin, p. 705.

${ }^{31}$ Yves-Pierre Boulongne (2000), no entanto, sugere que tomemos os posicionamentos e crenças de Coubertin dentro dos limites e da cultura de seu tempo e lugar, evidenciando até mesmo ainda alguns posicionamentos relativamente progressistas do patriarca olímpico em relação ao esporte feminino.
} 
Apesar do apoio dos delegados à incorporação da natação e do tênis femininos, a rejeição ao atletismo foi unânime. Em resposta, um "grupo de mulheres da Europa e dos EUA" organizou um exitoso encontro de atletismo em Monte Carlo, em 1921 e 1922 (vide fig. 2). ${ }^{32}$
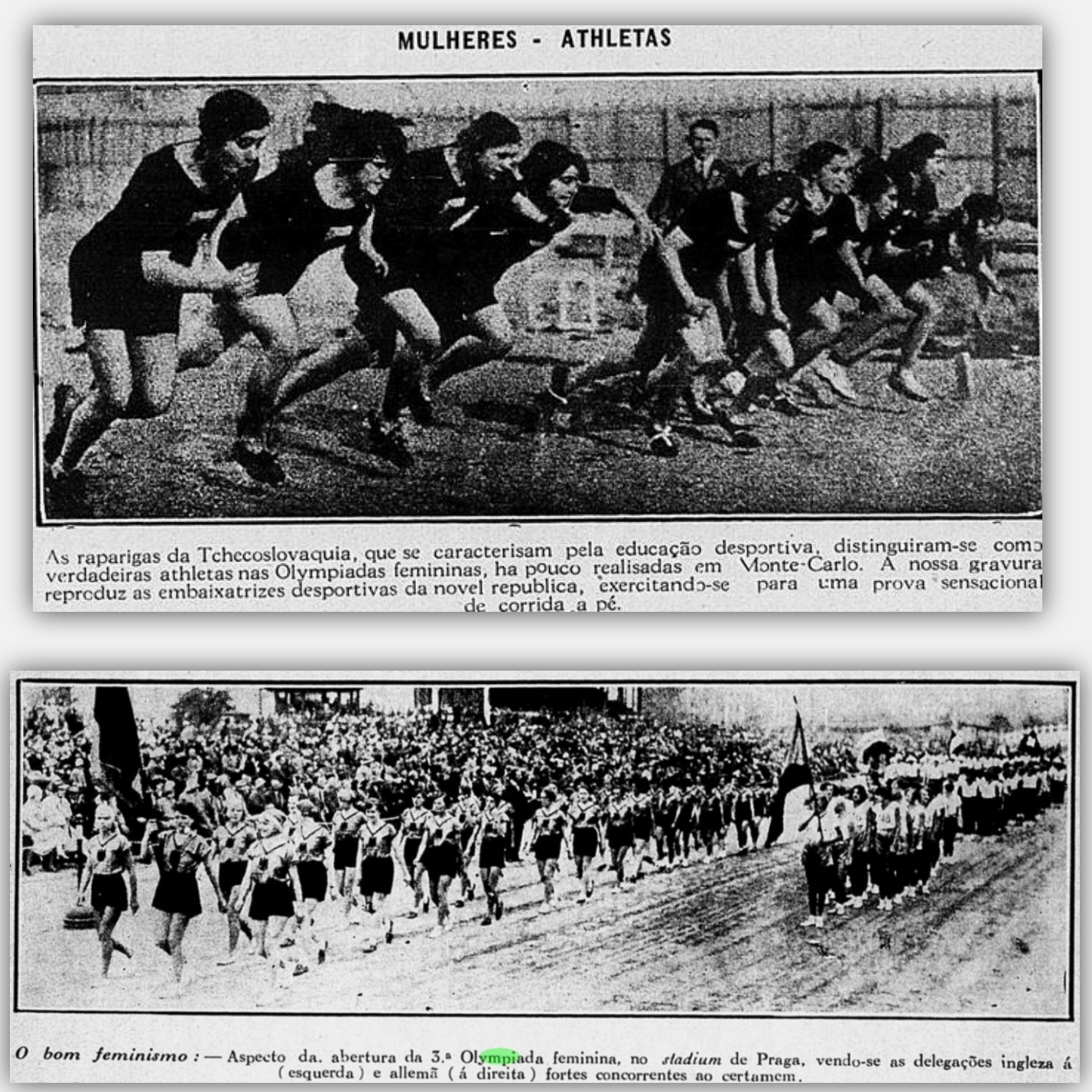

Figura 2 - Jogos femininos em Monte Carlo (acima) e em Praga (abaixo).

Fonte: Revista da Semana, 01/07/1922, p. 7 (acima); Eu sei tudo, fev. 1931, p. 104 (abaixo).

As participantes desse evento criaram, em outubro de 1921, a Federação Esportiva Feminina Internacional (FSFI, na sigla em francês). ${ }^{33}$ Em 1922, a FSFI realizou a primeira edição dos Jogos Mundiais Femininos (Women's World Games),

\footnotetext{
${ }^{32}$ HARGREAVES. Sporting Females, p. 211.

${ }^{33}$ Fédération Sportive Féminine Internationale.
} 
em Paris. Outras três edições foram realizadas em Gotemburgo (1926), Praga (1930) e Londres (1934). ${ }^{34}$ Um dado importante é que a FSFI não obteve autorização do COI para adicionar o termo "olímpico" ao nome do evento,35 o que não impediu a imprensa carioca de divulgar essas competições como "Olimpíadas Femininas". Cumpre destacar a dualidade contida nos discursos jornalísticos sobre esses "jogos olímpicos femininos". Um jornalista do Correio ressaltava que as participantes da edição de Praga, em 1930, eram "não somente belos espécimes do athletismo feminino, mas belas mulheres do ponto de vista estético". ${ }^{36}$ Fica evidente aqui que o esporte não era representado unicamente pelo viés dos benefícios e satisfação femininos, mas, principalmente, pelo contentamento que proporcionava aos homens. De acordo com Allen Guttmann, "os critérios para a atividade física das mulheres de classe média eram higiênicos e estéticos, em vez de atléticos".37 Também no Brasil, como destaca Devide, o "conceito de saúde esteve estreitamente relacionado com o de beleza estética, tornando-se indissociados e necessários às mulheres na virada do século XIX" ${ }^{38}$ Em acordo com essa perspectiva, as narrativas jornalísticas tendiam a valorizar os esportes que conservavam um corpo feminino dentro dos padrões socialmente desejados, enquanto aqueles que masculinizariam, como as lutas em geral, eram reprimidos. A "forma corporal idealizada" para a mulher devia estar, assim, adequada "às normas patriarcais hegemônicas". ${ }^{39}$

A emancipação feminina nos esportes despertava uma série de receios no público masculino. Os jornalistas externavam seus temores quanto a uma possível masculinização dos corpos femininos, o que provavelmente escondia dilemas psíquicos relacionados à perda do domínio masculino da força física. Como aponta Hargreaves, a “'aquisição de força, musculatura e habilidade atlética sempre foi autorizada para os homens, enquanto que para as mulheres é muito menos

\footnotetext{
${ }^{34}$ HARGREAVES. Sporting Females, p. 211.

${ }^{35}$ CHATZIEFSTATHIOU; HENRY. Discourses of Olympism, p. 35.

${ }^{36}$ Correio, 16 nov. 1930, p. 7.

${ }^{37}$ GUTTMANN. The Olympics, a history of the Modern Games, p. 45. "the criteria for middle-class women's physical activity were hygienic and aesthetic rather than athletic".

${ }^{38}$ DEVIDE. A natação como elemento da cultura física feminina no início do século XX, p. 141.

${ }^{39}$ GIULIANOTTI. Sport, p. 88. "fitting hegemonic patriarchal norms".
} 
valorizada e, em alguns casos, é denegrida"”. ${ }^{40}$ Esse assunto rondava o artigo "A mulher e os sports", que propunha logo de início a indagação: "O sport é necessário ao sexo fraco?". Em seguida, era apresentado o argumento central do texto: "Mas o que é preciso a todo o transe impedir é que a mulher se masculinize; que faça sport, que seja corajosa e forte, mas que fique mulher, bem feminina". ${ }^{41}$

Outro jornalista demonstrava preocupação semelhante, propondo que as mulheres não deveriam ingressar nos torneios esportivos internacionais, pois isso as conduziria "um dia a querer rivalizar com o companheiro homem, esquecendose da sua real função na natureza". ${ }^{42} 0$ próprio Coubertin, em conferência proferida em 1928 no Bureau International de Pédagogie Sportive, dizia: “Cultura física e cultura desportiva: sim. Isso é excelente para a jovem e para a mulher. Mas, no que concerne à natureza feminina, é preciso ter muito cuidado com essa rudez do esforço masculino". ${ }^{43}$

Ainda que eivados em preconceitos de fundo sociocultural, as justificativas para o alijamento feminino do esporte vinham amparadas em pressupostos pseudobiológicos, como a fragilidade corpórea e a preponderância da maternidade na vida da mulher, ${ }^{44}$ o que Goellner denomina de "feminilidade normalizada". ${ }^{45}$ Também Coubertin era partidário da ideia de que "o engajamento no esporte violaria o 'destino fixo' das mulheres como mães e companheiras dos homens". 46 $\mathrm{Na}$ sociedade brasileira das décadas iniciais do século $\mathrm{XX}$, as mulheres estavam "em sua maioria, limitadas à esfera da casa, como 'rainhas do lar', fortalecendo o tripé mãe, esposa e dona-de-casa, não sendo bem vistas se ganhassem vulto na esfera pública". ${ }^{47}$ Os discursos que associavam exercícios físicos e maternidade podiam ser encontrados "em diversos manuais e livros escritos no Brasil desde

\footnotetext{
${ }^{40}$ HARGREAVES. Querying Sport Feminism, p. 146. "The acquisition of strength, muscularity and athletic skill has always been empowering for men, whereas for women it is valued far less and in some cases is denigrated"'.

${ }^{41}$ Revista da Semana, 18 abr. 1925, p. 39-40.

42 Jornal dos Sports, 01 jul. 1931, p. 4.

${ }^{43}$ COUBERTIN. Pierre de Coubertin, p. 178.

${ }^{44}$ Sobre isso, esclarece Hargreaves (1994, p. 217): "A ética dos argumentos para proibir esportes perigosos, como o boxe, é tão apropriada para os homens quanto para as mulheres; a razão pela qual são aplicadas apenas às mulheres é cultural, não biológica".

45 GOELLNER. Jogos Olímpicos, p. 33.

${ }^{46}$ GIULIANOTTI. Sport, p. 82. "[...] that sport engagement would breach women's 'fixed destiny' as mothers and men's companions".

${ }^{47}$ DEVIDE. A natação como elemento da cultura física feminina no início do século XX, p. 136.
} 
meados do século XIX e também nas revistas direcionadas especificamente para o público feminino". 48

Na primeira participação olímpica brasileira, em 1920, a delegação, composta por 21 atletas e três dirigentes, não contava com nenhuma mulher entre seus integrantes, o que refletia a situação feminina não apenas no esporte, mas no âmbito mais geral da vida social. No ano seguinte, era publicado nos jornais cariocas o folheto "Qué es el olimpismo?", um texto informativo escrito por Coubertin em 1917.49 Nele, o presidente do COI discorria sobre os elementos do esporte e a essência do Olimpismo, abordando seus benefícios para as sociedades modernas e sua possível contribuição para a América Latina. 0 destinatário de suas recomendações era o homem moderno ocidental, ao passo que a relação das mulheres com o esporte era simplesmente ignorada. Não havia sequer uma menção à palavra "mulher" (e correlatas) em todo seu texto.

No cômputo geral, entretanto, o número de mulheres olímpicas avançava, o que tornava mais explícito os movimentos de oposição. Em referência à Olimpíada de Paris/1924, o artigo "A mulher e os sports", publicado na capa d'O Imparcial, alertava: "O número de mulheres que acorreram dos pontos mais diversos do globo constitui uma surpresa, que é, também, um perigo". 50 A consciência desse "perigo" era compartilhada pelos delegados do COI, que, reunidos no Congresso de Praga, em 1925, deliberaram pela restrição das modalidades femininas: "1o - que os sports acessíveis à mulher devem ser assimilados às suas capacidades physicas, porém, em todo caso, mais moderadas do que nos sports praticados pelos homens; $2^{\text {o }}$ - que o box, rugby, luta e football devem ser proibidos à mulher". ${ }^{51}$ Percebe-se como o esporte feminino estava assentado em bases pouco sólidas e como o ritmo do seu progresso era regido pelas "normas patriarcais". 52

\footnotetext{
${ }^{48}$ GOELLNER. Mulher e esporte no Brasil, p. 90.

${ }^{49}$ O texto foi publicado em várias partes n'O Imparcial nos dias 16, 25 e 29 de outubro e 8 e 11 de novembro de 1921. O jornal apresentava-o como "Manuscrito em francês, do barão de Coubertin, presidente do Comitê Olympico Internacional, dedicado à juventude da América Latina" (O Imparcial, 11 nov. 1921, p. 8). Em 1924, o folheto, que virou livro, voltaria a ser publicado, dessa vez pel'O Paiz (17 fev. 1924, p. 11).

50 O Imparcial, 20 ago. 1924, p. 1.

${ }^{51}$ O Paiz, 07 ago. 1925, p. 7.

${ }^{52}$ GIULIANOTTI. Sport, p. 83.
} 
A Carta Olímpica de 1924, que incluía pela primeira vez um item sobre a participação feminina, era exemplar desse progresso com rédeas curtas: "As mulheres são admitidas nos Jogos Olímpicos. 0 programa determinará as provas que elas poderão disputar". ${ }^{53}$ Paralelamente, a pressão da Federação Esportiva Feminina Internacional levou a Federação Internacional de Atletismo Amador (IAAF, em inglês) a recomendar, em 1926, a participação feminina em cinco provas de atletismo (100 e $800 \mathrm{~m}$, salto em altura, lançamento de disco e $400 \mathrm{~m}$ com barreiras), o que foi acatado pelo COI. ${ }^{54}$ Para Hargreaves, não era fortuita essa inclusão ter se dado após a saída de Coubertin da presidência do COI. ${ }^{55}$ Nesse avançar claudicante, até mesmo o Papa Pio XI declarava publicamente, em 1928, sua discordância quanto às competições públicas de atletismo feminino. ${ }^{56}$

Suplantando os antagonismos, as mulheres se fizerem presentes nas provas de atletismo em Amsterdã/1928, sendo destacado pelo jornal $A$ Noite que a performance de algumas dessas atletas teria sido superior à de "muitos homens de alguns países". ${ }^{57}$ Não obstante, devido a incidentes após a prova de $800 \mathrm{~m}$, quando muitas atletas desmaiaram, a IAAF decidiu eliminar essa prova olímpica para mulheres, sob a justificativa de ser "demasiado forte para o organismo feminino". 58 Nessa mesma deliberação, foram ainda excluídas as provas de 200 metros, salto em distância e arremesso de peso. ${ }^{59}$ Em 1929, o presidente do COI, Baillet-Latour, sugeriu, sem sucesso, ao Conselho Executivo da entidade a limitação dos esportes femininos à ginástica, natação, tênis e patinação artística. ${ }^{60}$ Ainda repercutindo esse incidente, Coubertin escreveria, em novembro de 1928, um artigo para o Le Sport Suisse contrário a presença de atletas mulheres nos Jogos: "Se há mulheres que querem jogar futebol ou lutar boxe, são muito livres para fazer isso, sempre e

\footnotetext{
53 “Les femmes sont admises aux Jeux Olympiques. Le programme fixera les épreuves qu'elles pourront disputer".

54 GOLDSTEIN. Amsterdam 1928, p. 92.

55 HARGREAVES. Sporting Females, p. 213.

${ }^{56}$ GOLDSTEIN. Amsterdam 1928, p. 92.

${ }^{57}$ A Noite, 09 dez. 1932, p. 7

58 O Paiz, 04 out. 1928, p. 17. O banimento de provas femininas de 800 metros durou até os Jogos de 1960 (GOLDSTEIN, 2004, p. 92).

59 GOLDSTEIN. Amsterdam 1928, p. 92.

${ }^{60}$ GUTTMANN. The Olympics, a history of the Modern Games, p. 49.
} 
quando não haja espectadores, porque os que assistem a tais competições não vão em absoluto a ver o esporte. ${ }^{61}$

Em outro documento, a "Carta para Reforma do Esporte" de 1930, Coubertin assinalava o afastamento feminino como uma das medidas a ser tomadas para correção dos rumos do esporte: "Supressão da admissão das mulheres em todas as provas nas quais participem homens". ${ }^{62}$ Mesmo entidades femininas possuíam na época visões divergentes a respeito do esporte de alto rendimento para mulheres. A divisão feminina da National Amateur Athletic Federation (EUA) dirigiu ao COI uma solicitação para eliminação das provas femininas em Londres/1932, sob o argumento de que "tais provas desenvolvem e estimulam lamentavelmente orgulhos individuais ou de grupos e cooperam na mercantilização do sport”. 63 Em ocasião anterior, a feminista australiana Rose Scott se opôs à inclusão da natação nos Jogos de 1912, pois acreditava que a exibição de corpos femininos atrairia mais voyeurs do que fãs de esporte. ${ }^{64} \mathrm{~A}$ própria Alice Milliat, fundadora da FSFI, demonstrara certo incômodo com o uso de roupas esportivas pelas mulheres diante de "grandes multidões". 65 Esse argumento contrário à exposição pública seria mais uma vez reiterado por Coubertin em discurso radiofônico, em 1935: "Pessoalmente, não aprovo a participação de mulheres em competições públicas, o que não significa que se devam abster de praticar um grande número de esportes, com a condição de que não sejam um espetáculo". 66

Para os Jogos de 1932, o Brasil, pela primeira vez em sua história, contaria com uma atleta em sua delegação nacional. Um atraso considerável, se lembrarmos que primeira participação olímpica feminina ocorrera 32 anos antes. A nadadora Maria Lenk, a atleta em questão, não era, contudo, a única mulher nessa delegação. Meses antes do embarque da representação brasileira rumo a Los Angeles, dois jornais cariocas (Diário de Notícias e Jornal dos Sports) organizaram um concurso para premiar um homem e uma mulher com passagens e hospedagem para a Olimpíada de 1932. A eleição da Rainha da Embaixada Esportiva do Brasil e do

\footnotetext{
${ }^{61}$ COUBERTIN. Pierre de Coubertin, p. 178-179.

${ }^{62}$ COUBERTIN. Pierre de Coubertin, p. 227.

${ }^{63}$ O Paiz, 09-10 jun. 1930, p. 3.

${ }^{64}$ GUTTMANN. The Olympics, a history of the Modern Games, p. 33.

65 Jornal do Brasil, 12 abr. 1928, p. 12.

${ }^{66}$ COUBERTIN. Pierre de Coubertin, p. 575.
} 
Embaixador da Torcida Brasileira ocorreu por meio de cupons encartados diariamente nos referidos periódicos entre dezembro de 1931 e maio de 1932 . Os leitores preenchiam esses cupons e os encaminhavam às redações dos jornais com as suas escolhas para os postos de Rainha e Embaixador.

Sobre esse concurso, o ponto que me interessa para este artigo é a discrepância entre os critérios de escolha no concurso masculino e no feminino. Se bastava ao candidato a "Embaixador" ser o mais votado pelos leitores, ${ }^{67}$ a escolhida para "Rainha" tinha ainda de passar pelo escrutínio do jornal e pela avaliação de um júri. Primeiramente, as dez candidatas mais votadas tiveram de responder a um questionário, que incluía perguntas sobre altura, peso, cintura, busto. ${ }^{68}$ Em uma segunda etapa, um júri escolhido pelo $J S$ analisou aspectos como os idiomas dominados pelas candidatas, os esportes por elas praticados e as habilidades em música e dança. ${ }^{69}$ Não bastava se dizer torcedora de um clube, era requerido que as mulheres apresentassem provas dessa paixão. 0 mesmo expediente não era exigido dos homens. Além disso, os atributos avaliados (línguas, música, esporte) limitavam a escolha a senhoras e senhoritas da elite carioca, excluindo da disputa as mulheres de origem mais humilde. Isso evidencia os critérios não apenas sexistas, como também classistas, que orientaram esse concurso e que, de modo geral, dizem respeito ao lugar da mulher no esporte à época.

Na partida do navio Itaquicé rumo a Los Angeles, em 25 de junho de 1932, entre nadadores, saltadores, jogadores de polo aquático, atiradores, remadores, corredores, levantadores e arremessadores de peso, Maria Lenk se sobressaía como a única atleta do sexo feminino. Yvone Padilha e Lydia von Ihering, ganhadoras do supracitado concurso, eram denominadas pelo jornal $A$ Noite de "Guardas de Maria Lenk". ${ }^{70}$ Getúlio Vargas, ao subir a bordo do navio, fez questão de saudar Lenk, elogiando seus "predicados eugênicos", que bem representariam a

\footnotetext{
${ }^{67}$ O concurso masculino foi encerrado em seis de junho (JS, 05 jun. 1932, p. 2), coroando Affonso Segreto, amparado pelos votos dos torcedores do Flamengo (09 jun. 1932, p. 1).

${ }^{68}$ Jornal dos Sports, 02 jun. 1932, p. 1.

${ }^{69}$ Pela avaliação desses critérios, Yvone Padilha, a $2^{\mathrm{a}}$ mais votada, foi selecionada Rainha (JS, 14 jun. 1932, p. 1). Cedendo ao apelo da torcida rubro-negra, o JS também agraciou Lydia Von Ihering, a candidata mais votada, com uma viagem para Los Angeles (JS, 18 jun. 1932, p. 3).

${ }^{70}$ A Noite, 24 jul. 1932, p. 7.
} 
"mulher brasileira no grande prelo sportivo das raças". ${ }^{71}$ Cumpre lembrar que, em fevereiro daquele mesmo ano, Vargas, cedendo a pressões, havia promulgado um Código Eleitoral que instituía avanços importantes nos direitos políticos individuais, como o voto obrigatório e secreto para homens e mulheres. ${ }^{72}$ Era a $1^{\underline{a}}$ vez que as mulheres brasileiras poderiam votar e ser votadas. ${ }^{73}$

A natação, esporte praticado por Lenk, se enquadrava na seara de esportes bem vistos socialmente, pois possuía "traços convergentes com aquilo que se interpretava como 'natureza feminina'". ${ }^{74}$ Essa pode ser uma das razões a explicar o apreço da imprensa e o reconhecimento das autoridades esportivas e políticas pela nadadora brasileira. Nas brechas desse discurso simpático à atleta, sobreviviam, porém, palavras como as do jornalista Edgar Proença: "Espiritualmente bela, a sua simplicidade arrebata, pondo no coração da gente o desejo de prendê-la, de tê-la prisioneira de nosso encanto numa época em que as mulheres se banalizam". ${ }^{75}$

A participação feminina, ao lado do amadorismo, foi o grande foco de discussão internacional nos Jogos de $1932 .{ }^{76}$ Um pouco antes daquela Olimpíada ainda permanecia um clima de incerteza sobre o programa olímpico feminino. 0 Comitê organizador norte-americano chegou a enviar um ofício à Confederação Brasileira de Desportos, responsável pela organização da representação brasileira, com "as condições em que as mulheres poderão tomar parte nas Olympiadas de Los Angeles, em 1932". ${ }^{77} \mathrm{Na}$ Itália, o Papa Pio XI opinava novamente sobre a questão olímpica, dessa vez recomendando que a equipe italiana proibisse a participação feminina. ${ }^{78}$ Finda a competição, $A$ Noite publicava uma imagem de uma prova de luta livre feminina que destacava em seu título: "Nem a luta livre escapa da invasão feminina". ${ }^{79} \mathrm{~A}$ despeito dos obstáculos, todos os cinco eventos

\footnotetext{
${ }^{71}$ O Jornal, $2^{a}$ seção, 26 jun. 1932, p. 4-5.

${ }^{72}$ FAUSTO. História concisa do Brasil, p. 190-191.

73 SCHWARCZ; STARLING. Brasil, p. 362.

74 DEVIDE. A natação como elemento da cultura física feminina no início do século XX, p. 136.

75 O Jornal, 30 out. 1932, $2^{a}$ seção, p. 4.

${ }^{76}$ PIEROTH. Los Angeles 1932, p. 96.

77 Jornal dos Sports, 26 abr. 1931, p. 1.

78 KANIN. A political history of the Olympic Games, p. 49.

${ }^{79}$ A Noite, 05 jan. 1933, p. 8.
} 
do atletismo feminino disputados em 1932 registraram quebra de recordes mundiais ${ }^{80}$ e arrebataram o público norte-americano. ${ }^{81}$

O sucesso feminino em Los Angeles/1932 não foi, no entanto, suficiente para refrear o aparelho burocrático oficial em sua oposição sistemática ao esporte competitivo para mulheres. A Carta Olímpica de 1933 ratificava a posição do esporte feminino enquanto concessão, deixando claras suas possíveis restrições: “Mulheres não são excluídas, mas o Comitê Olímpico Internacional, se solicitado por uma Federação Internacional, decide os eventos em que elas podem participar". 82

A filosofia olímpica nesse período acompanhava em grande medida o que pensava o fundador e presidente do COI. Com algumas variações de forma, o conteúdo dos discursos de Pierre de Coubertin sobre as mulheres pouco mudara. Em 1935, em discurso radiofônico irradiado internacionalmente, Coubertin reiterava sua desaprovação à participação feminina em "competições públicas" com caráter de espetáculo, a menos que estivessem na condição de coadjuvantes: "Seu papel nos Jogos Olímpicos deveria ser, essencialmente, como nos antigos torneios, o de coroar os vencedores". 83

Para 1936, se esboçava ao menos uma notícia promissora para as mulheres esportivas. Pela primeira vez, uma jornalista atuaria como correspondente olímpica de uma folha carioca. Maria de Monte Silveira enviava desde 1935 notícias sobre os preparativos olímpicos direto da Europa para o Jornal dos Sports. ${ }^{84}$ Essa é, todavia, uma história que ficará para ser contada em outras pesquisas.

\section{CONSIDERAÇõES FINAIS}

De 1920 em diante, houve um crescimento da presença da mulher nos Jogos Olímpicos, resultado direto das lutas feministas naquele período. Vassil Girginov

\footnotetext{
${ }^{80}$ GUTTMANN. The Olympics, a history of the Modern Games, p. 47.

${ }^{81}$ PIEROTH. Los Angeles 1932, p. 100.

82 INTERNATIONAL OLYMPIC COMMITTEE (IOC). Olympic Charter, p. 14. "Women are not excluded but the International Olympic Committee, if requested by an International Federation, decides the events in which they may take part".

${ }^{83}$ COUBERTIN. Pierre de Coubertin, p. 575.

${ }^{84}$ Jornal dos Sports, 13 mar. 1935, p. 4.
} 
nos alerta que "por trás das reivindicações do Olimpismo de Pierre de Coubertin para o universalismo há uma lógica de exclusão praticamente inalterada hoje, que é evidente em três níveis - culturas nacionais, divisão de classes e gênero". 85 Nesse sentido, reside no Movimento Olímpico Moderno uma dicotomia fundamental. Se, por um lado, o Olimpismo promove uma ideologia pacifista, internacionalista e de integração, por outro, incentiva ou é conivente com preconceitos de toda ordem (raça, classe social, gênero). Neste artigo, o centro de discussão foi a exclusão de gênero, isto é, o cerceamento e a imposição de obstáculos à participação feminina no mundo olímpico.

Ao longo da pesquisa para a redação deste trabalho pude observar as temáticas que circulavam com mais frequência em torno do feminino no esporte: graciosidade, beleza, maternidade. No período aqui investigado, as mulheres ainda eram encaradas como intrusas no campo olímpico, atletas de segunda classe. De modo mais amplo, Giglio conclui que os preceitos predominantes no movimento olímpico durante o século XX seguem o "paradigma instituído por Coubertin e seus contemporâneos da mulher frágil e de participação inadequada em modalidades esportivas consideradas viris". ${ }^{86}$ De fato, apenas em fins do século XX e início do XXI é que as mulheres experimentariam algo próximo à igualdade dentro do Movimento Olímpico Internacional.

O item "Participação das mulheres", inserido na Carta Olímpica em 1924, permaneceu nesse documento, com algumas alterações, até a edição de 1987. De 1894 a 1980, o COI simplesmente não possuía nenhuma mulher entre seus membros. As duas primeiras delegadas olímpicas - a venezuelana Flor Isava Fonseca e a finlandesa Pirjo Häggman - foram eleitas em $1981 .{ }^{87}$ Até 2012, dos 110 delegados olímpicos somente 19 eram mulheres. ${ }^{88} 0$ número de esportes coletivos olímpicos masculinos e femininos se igualaria apenas na Olimpíada de Sydney/2000. ${ }^{89}$ Atenas/2004 foi a primeira edição na qual o percentual de atletas

\footnotetext{
${ }^{85}$ GIRGINOV. Does one-world Olympic ideology lead to multiculturalism?, p. 363. "behind the claims of Pierre de Coubertin's Olympism for universalism lies a logic of exclusion largely unchanged today which is evident at three levels - national cultures, class division and gender". ${ }^{86}$ GIGLIO et al. Desafios e percalços da inserção da mulher nos Jogos Olímpicos (1894-1965), p. 11.

87 INTERNATIONAL OLYMPIC COMMITTEE (IOC). Olympic Charter, p. 2.

${ }^{88}$ MIAH; GARCÍA. The Olympics, p. 17.

${ }^{89}$ GIULIANOTTI. Sport, p. 86.
} 
do sexo feminino ultrapassou a marca de $40 \%$. Esses e outros fatos evidenciam que a paridade no esporte é uma experiência bem recente.

Acredito que o esporte e o jornalismo esportivo acompanham os ditames de seu tempo, ainda que porventura possam estar na vanguarda em alguns assuntos. No caso do esporte feminino, tanto as instituições olímpicas oficiais quanto o jornalismo carioca estavam em sintonia com os discursos de seu tempo, alicerçados em um papel fixo da mulher na sociedade e na subordinação ao elemento masculino. Coube às próprias mulheres, como vimos aqui, reivindicar seus espaços em um mundo essencialmente masculino, como era o olímpico.

\section{REFERÊNCIAS}

A NOITE (jornal), Rio de Janeiro, 1930-1935.

BIRRELL, Susan. Feminist Theories for Sport. In: COAKLEY, Jay; DUNNING, Eric (Orgs.). Handbook of Sports Studies. Londres: SAGE Publications, 2007, p. 61-76.

BOULONGNE, Yves-Pierre. Pierre de Coubertin and women's sport. Olympic Review, XXVI-31, fev.-mar, 2000, p. 23-26.

CARETA (revista), Rio de Janeiro, 1920-1935.

CHATZIEFSTATHIOU, Dikaia; HENRY, Ian. Discourses of Olympism. From the Sorbonne 1894 to London 2012. Houndmills: Palgrave Macmilan, 2012.

CORREIO DA MANHÃ (jornal), Rio de Janeiro, 1901-1935.

COUBERTIN, Pierre. Pierre de Coubertin: Olimpismo - Seleção de textos (Norbert Muller e Nelson Schneider Todt [Editores]). Porto Alegre: ediPUCRS, 2015.

DEVIDE, Fabiano Pries. A natação como elemento da cultura física feminina no início do século XX: construindo corpos saudáveis, belos e graciosos. Revista Movimento, v. 10, n. 2, mai.-ago. 2004.

EU SEI TUDO (revista), Rio de Janeiro, 1920-1935.

FON FON (revista), Rio de Janeiro, 1920-1935. 
GAZETA DE NOTÍCIAS (jornal), Rio de Janeiro, 1890-1934.

FAUSTO, Boris. História concisa do Brasil. São Paulo: Editora da Universidade de São Paulo, 2006.

GIGLIO, Sérgio; GALATTI, Larissa; MACHADO, Gisele; ALTMANN, Helena; PAES, Roberto; SEONE, Antonio. Desafios e percalços da inserção da mulher nos Jogos Olímpicos (1894-1965). Recorde, Rio de Janeiro, v. 11, n. 1, p. 122, jan.-jun. 2018.

GIRGINOV, Vassil. Does One-world Olympic Ideology Lead to Multiculturalism?. In: GIRGINOV, Vassil (Org.). The Olympics: A Critical Reader. Nova York: Routledge, 2010b, p. 361-372.

GIULIANOTTI, Richard. Sport: A Critical Sociology. Cambridge (UK): Polity Press, 2005.

GOELLNER, Silvana Vilodre. Mulher e esporte no Brasil: entre incentivos e interdições elas fazem história. Revista Pensar a Prática, Goiás, v. 8, n. 1, 2005, p. 85-100.

GOELLNER, Silvana Vilodre. Jogos Olímpicos: a generificação de corpos performantes. Revista USP, São Paulo, n. 108, p. 29-38, 2016.

GOLDSTEIN, Edward S. Amsterdam 1928. In: FINDLING, John; PELLE, Kimberly (Eds.). Encyclopedia of the Modern Olympic Movement. Londres: Greenwood Press, 2004, p. 89-94.

GUTTMANN, Allen. The Olympics, a History of the Modern Games. Urbana, Chicago: University of Illinois Press, 1992.

HARGREAVES, Jennifer. Sporting Females: Critical Issues in the History and the Sociology of Women's Sport. Londres: Routledge, 1994.

HARGREAVES, Jennifer. Querying Sport Feminism: Personal or Politcal? In: GIULIANOTTI, Richard (Org.). Sport and Modern Social Theorists. Hampshire (UK), Nova York: Palgrave MacMillan, 2004, p. 187-206.

HORNE, John; TOMLINSON, Alan; WHANNEL, Garry. Understanding Sport: An Introduction to the Sociological and Cultural Analysis of Sport. Londres: Routledge, 1999.

INTERNATIONAL OLYMPIC COMMITTEE (IOC). Olympic Charter, 02 ago. 2015. Disponível em: https://bit.ly/36leVM9. Acesso em: 20 dez. 2019.

INTERNATIONAL OLYMPIC COMMITTEE (IOC). Olympic Charter: The International Olympic Committee and the Modern Olympic Games. Charte des Jeux Olympic. Lausanne: COI, 1933.

JORNAL DO BRASIL (jornal), Rio de Janeiro, 1891-1935.

JORNAL DOS SPORTS (jornal), Rio de Janeiro, 1930-1935.

KANIN, David B. A Political History of the Olympic Games. Colorado: Westview Press, 1981. 
MELO, Victor Andrade de. Corpos, bicicletas e automóveis: outros esportes na transição do século XIX para o XX. In: PRIORE, Mary Del; MELO, Victor Andrade de (Orgs.). História do esporte no Brasil: do Império aos dias atuais. São Paulo: Editora UNESP, 2009, p. 71-106.

$\mathrm{MIAH}$, Andy; GARCÍA, Beatriz. The Olympics: the basics. Nova lorque: Routledge, 2012.

O IMPARCIAL (jornal), Rio de Janeiro, 1912-1935.

O PAIZ (jornal), Rio de Janeiro, 1890-1934.

O MALHO (revista), Rio de Janeiro, 1920-1935.

O JORNAL (jornal), Rio de Janeiro, 1930-1935.

PIEROTH, Doris. Los Angeles 1932. In: FINDLING, John; PELLE, Kimberly (Eds.). Encyclopedia of the Modern Olympic Movement. Londres: Greenwood Press, 2004, p. 95-104.

REVISTA DA SEMANA (revista), Rio de Janeiro, 1900-1935.

SCHWARCZ, Lilia Moritz; STARLING, Heloisa Murgel. Brasil: uma biografia. São Paulo: Companhia das Letras, 2015.

SPORT ILUSTRADO (revista), Rio de Janeiro, 1920-1935.

THEBERGE, Nancy. Gender and Sport. In: COAKLEY, Jay; DUNNING, Eric (Orgs.). Handbook of Sports Studies. Londres: SAGE Publications, 2007, p. 322-333.

Recebido para publicação em: 22 set. 2019.

Aprovado em: $18 \mathrm{dez} .2019$. 